

\section{NOTICE}

The submitted manuscript has been offered by an employee of the Alliance for Sustainable Energy, LLC (ASE), a contractor of the US Government under Contract No. DE-AC36-08-GO28308. Accordingly, the US Government and ASE retain a nonexclusive royalty-free license to publish or reproduce the published form of this contribution, or allow others to do so, for US Government purposes.

This report was prepared as an account of work sponsored by an agency of the United States government. Neither the United States government nor any agency thereof, nor any of their employees, makes any warranty, express or implied, or assumes any legal liability or responsibility for the accuracy, completeness, or usefulness of any information, apparatus, product, or process disclosed, or represents that its use would not infringe privately owned rights. Reference herein to any specific commercial product, process, or service by trade name, trademark, manufacturer, or otherwise does not necessarily constitute or imply its endorsement, recommendation, or favoring by the United States government or any agency thereof. The views and opinions of authors expressed herein do not necessarily state or reflect those of the United States government or any agency thereof.

Available electronically at http://www.osti.gov/bridge

Available for a processing fee to U.S. Department of Energy and its contractors, in paper, from:

U.S. Department of Energy

Office of Scientific and Technical Information

P.O. Box 62

Oak Ridge, TN 37831-0062

phone: 865.576.8401

fax: 865.576 .5728

email: mailto:reports@adonis.osti.gov

Available for sale to the public, in paper, from:

U.S. Department of Commerce

National Technical Information Service

5285 Port Royal Road

Springfield, VA 22161

phone: 800.553.6847

fax: 703.605.6900

email: orders@ntis.fedworld.gov

online ordering: http://www.ntis.gov/ordering.htm 


\title{
Applying Systems Engineering in a Renewable Energy Research \& Development Environment
}

\author{
Neil Snyder \\ National Renewable Energy \\ Laboratory \\ neil.snyder@nrel.gov
}

\author{
Mark Antkowiak \\ National Renewable Energy \\ Laboratory \\ mark.antkowiak@nrel.gov
}

\begin{abstract}
Systems Engineering (SE) practice has largely developed around a few specific industries, especially aerospace/defense and IT. SE is well understood by, and remains associated with, these industries. The classical systems engineering process starts with conceptual development of a specific system that will ultimately be produced and deployed. In the renewable energy R\&D environment, neither of these normal cases apply; the work is being conducted in a culture that is generally unfamiliar with systems engineering, and the R\&D activities are mostly oriented toward technology development and refinement rather than toward development of a specific deployable system. Nevertheless, systems engineering principles can be applied to enhance the management of the Research \& Development (R\&D) process, but significant tailoring of SE processes is required, and enhanced modeling and simulation techniques must be applied to deal with all the unknowns at a very early part of the system lifecycle. The lessons learned from several years of experience in this unique environment at the National Renewable Energy Laboratory, as well as a number of new ideas for future process enhancements, will be explored in this paper.
\end{abstract}

\section{Introduction}

The Systems Engineering and Program Integration Office (SEPIO) at the National Renewable Energy Laboratory (NREL) has been supporting the Office of Energy Efficiency and Renewable Energy (EERE) within the Department of Energy (DOE) since 2003. This support is provided to several programs that are primarily engaged in applied R\&D, including the Hydrogen \& Fuel Cells, Biomass, Vehicle Technologies, and Geothermal Programs. The EERE mission statement states in part that it "works to strengthen the United States' energy security, environmental quality, and economic vitality in public-private partnerships". This mission statement does not state that EERE is directly responsible for something like putting a man on the moon or building a new aircraft carrier, as would be expected in a typical NASA or DOD program; rather, it implies that EERE is responsible for moving the state of technology forward through partnerships with industry and other players. This is a critical difference from typical NASA/DOD missions, and it turns out that this has a large impact on the application of classical systems engineering principles, developed in the NASA/DOD environment, to this customer's mission.

As an example of the foregoing, consider that the lack of a physical object as the program goal and the lack of metrics by which to measure success inhibit and severely complicate the development of system requirements. Program metrics could be developed, and goals are often set based on the technology and the program mission, but these are always subject to change not only with the changing state of the technology, but also with very powerful geopolitical and economic forces that impact the program from one Congress or Administration 
to the next. These forces have a much stronger impact on EERE than on a typical design and build project, and cause goals and requirements to constantly shift and evolve.

When SEPIO was formed, a plan was written to define the mission of the office and the expected tools and processes that the office would use to execute this mission. These original expectations on tools and processes were largely derived from classical SE practice, and after a few years it became clear that not everything was working as planned. This paper will examine which classical elements proved useful in this environment, and it will then go on to describe some newer approaches that have been implemented. However, the bulk of this paper will focus on some emerging tools and processes that may be more applicable in this unique environment.

\section{Apply Classical SE Tools}

Classical systems engineering (SE) tools should in theory be applicable, at least to some degree, in all parts of the system lifecycle. When SEPIO was first formed, the primary functions for the organization were defined as: establish and maintain the baseline, analyze the system and program, and verify technical performance. The baseline function was expected to be further broken down into mission analysis, functional analysis, and alternatives identification. The analysis function was expected to utilize modeling \& simulation, trade studies, risk analysis, and decision analysis. Finally, the verification function was expected to utilize the techniques of analysis, evaluation, test, and demonstration. All of these elements are familiar to practicing SEs from any industry.

The significance of this list of SE elements is not what it includes, but rather what it does not include. In a broad sense, with regard to the often-discussed systems engineering "V", what is missing is the lower portion of the "V", the portion where subsystem and component design, manufacture, and test are performed. A comparison of the SE element list to the larger list of elements contained in the INCOSE Systems Engineering Handbook reveals many missing technical process elements, including: architectural design, implementation, transition, validation, operation, maintenance, and disposal; a similar comparison to the project process elements yields only one missing element, project control. (INCOSE, 2007) The absence of many technical elements is consistent with the EERE mission, which is focused upon $R \& D$ and downstream validation that requirements have been met; the missing elements belong to the middle stages of the development process, which are typically performed by industry. While this application of a subset of the classical SE toolbox may not fit well within the traditional practice of systems engineering, it does serve the purpose of providing a technical management process for renewable energy R\&D.

The reason for the absence of a project controls function is not obvious. The most straightforward explanation is that there is not a hard driver for the function, given that EERE is not responsible for development activities leading to specific products. A secondary reason is the academic orientation of the EERE culture; there is resistance by R\&D professionals to any controls on their work processes, as they often consider such controls as irrelevant to the research mission.

Details of SEPIO applications of classical SE tools have been documented in previous presentations. In "Systems Integration and the Department of Energy's Hydrogen Program", the development of an integrated baseline using a model-based systems engineering tool is described. (Duffy, 2007) In "A System-of-Systems Framework for the Future Hydrogen Economy", the current energy System of Systems (SoS) is described, followed by a vision and transition strategy for a future hydrogen energy SoS, and finally a description of the model-based systems engineering tools that are used to track progress toward a future hydrogen economy. (Duffy, Sandor, 2008) In "Transforming From Petroleum to Biofuels: A System-of-Systems Perspective", the current transportation fuel SoS is described, followed 
by a vision and transition strategy for a future biofuels SoS, and finally a description of how system dynamics can be used to understand and accelerate the transition to a future transportation fuel SoS. (Riley, Sandor, 2008)

\section{Apply Enhanced Modeling \& Simulation}

Some modeling and simulation is typically present in SE activities, but it is not necessarily a major component of these activities. It can be argued that a primary use for modeling and simulation is to avoid the risk of failing to meet mission and performance requirements on large, complex projects. (INCOSE, 2007) However, in the renewable energy $R \& D$ environment, the nature of modeling and simulation is significantly different from that found in other SE activities. Projections of the future state are not limited just to technology development, but rather must include expectations of the marketplace, and the potential impacts of a variety of governmental policies on the marketplace. Thus, modeling and simulation activities are a combination of technical and socio-economic-political forecasting, requiring inputs, outputs, and interfaces well outside the technical realm.

Two major models have been developed by SEPIO to address the complexities of specific renewable energy technologies: the Hydrogen Program Macro-System Model (MSM) and the Biomass Program Biomass Scenario Model (BSM). Each of these models incorporates the unique aspects of the program it supports in order to provide a useful tool for simulating the future state of the technology in various socio-political environments. Both of these models represent a significant departure from the types of SE models typically described in SE reference documents. (INCOSE, 2007)

The MSM is intended to provide the capability for performing rapid, cross-cutting analysis by utilizing and linking other hydrogen models; these analyses can be used to support decisions regarding programmatic investments through analyses and sensitivity runs, and to support estimates of program outputs and outcomes. The model is being developed using a federated object model framework; this framework allows continued use of supporting component models, while providing a common platform for data exchange necessary to update integrated models when component models have been updated. (Ruth, 2009)

The BSM is intended to help explore how rapidly biofuel technologies might be deployed to make a significant contribution to the country's transportation energy supply. It models the entire supply chain to strategically assess R\&D and deployment strategies. It tracks the deployment of ethanol given development of new technologies, and the reaction of the investment community to those technologies in light of the competing oil market, vehicle demand for biofuels, and various government policies over time. The BSM uses the system dynamics framework for its conceptual underpinnings to understand the dynamic interactions across the entire biomass-to-biofuels system, or supply chain. This supply chain, in turn, provides a broad landscape for considering the emergence of a sustainable industry.

\section{Apply Complex Systems Thinking}

The processes described in the first two steps have been working well for dealing with individual renewable energy RD\&D programs; however, the next challenge is to be able to address how to plan for the distant future, taking into consideration all energy options. The classical SE tools support planning and execution in the 5 year timeframe. Adding enhanced modeling and simulation allows projections out into the 10 to 15 year timeframe. But the really hard questions that are now being asked in the world of energy are focused on how energy systems will evolve in the 20 to 40 year timeframe; these questions are driven both by rapidly increasing global demands for energy and by concerns about climate change.

It is useful to reflect on the world of 40 years ago when trying to establish a method for 
defining the world 40 years in the future. In 1970, the US was busy exploring the moon, fighting the Vietnam War and the larger Cold War, and going through major social changes; these social changes included the establishment of the environmental movement. In the energy arena, few people were concerned about coal-fired plants, numerous nuclear plants were being built, gasoline was cheap and plentiful, renewable energy development was minimal, and energy demand from so-called third world countries was insignificant. Global warming was not a concern for the average person. When comparing these facts to where we are in 2010, it is obvious that many circumstances could not have been predicted.

The approach for developing an energy strategy for the next 40 years will require not only projections of energy technology, but assumptions concerning social, political, and economic changes that will affect global energy. Complex systems theory can provide some possible approaches; details will be considered in the following sections.

\section{View Renewable Energy as a Complex System}

Renewable energy development requires engineering and fielding a suite of quite diverse technologies. It also requires integration with, and potentially eventual displacement of, massive existing infrastructures in both the transportation and electricity sectors. All of these factors clearly support the assumption that the transformation to large-scale utilization of renewable energy technologies constitutes a very complex system. One way of visualizing this complexity is to simply look at energy use in the US; see Figure 1. Of course, the production side of this picture is even more complex, involving both domestic and foreign production activities. There has been considerable interest in recent years in pursuing very aggressive changes to the status quo, driven in part by those who advocate rapid reductions in carbon emissions, and also driven more broadly by the general public when fuel prices spike, as they did most recently in 2008 .

Estimated U.S. Energy Use in 2008: 99.2 Quads

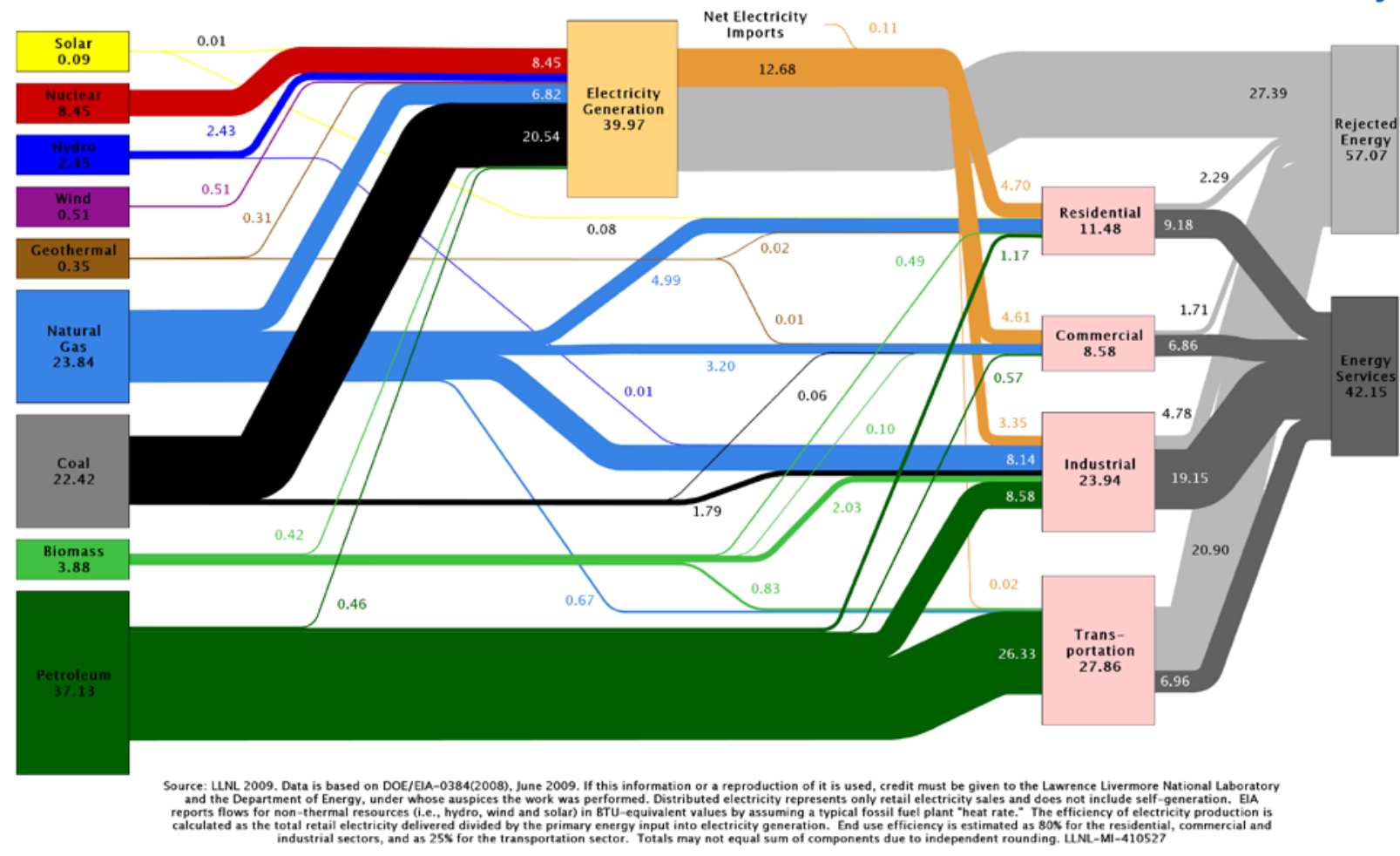

Figure 1. Estimated U.S. Energy Use in 2008 (LLNL, 2009) 
This level of interest has spawned numerous studies, both technical and economic. The emerging bottom line from these studies is that rapid, massive change is in many cases not realistic; even if fuel prices rose dramatically, changing the economic equations, there are many barriers to engineering, manufacturing, and deploying new infrastructures that will tend to limit the speed of change.

The good news about a somewhat slower rate of change is that it tends to put some bounds on the complexity problem. The idea of truly revolutionary changes to the energy economy creates an image of such extreme complexity that it is hard to envision how to effectively model all the potential changes, even at the conceptual level.

One of the key contextual variables needed to understand complex systems is the definition of overarching system architecture. If an architecture can be established in such a way that it is relatively stable overall, it can provide a basis for managing dramatic changes at more detailed levels. (Moses, 2004) Thus, the first step in defining the process for wide adoption of renewable energy technologies should be development of high level architectures, based to a considerable degree on existing technologies and infrastructures; at a minimum, there should be one architecture for electricity and one for vehicles and fuels. In an even broader sense, the total energy picture includes a third major element - direct heating from renewable sources. Taken together, these elements would comprise the full renewable energy architecture.

The deployment and integration of renewable energy technologies into society can be broken down into incremental changes to the high level architecture. The need for changes to the electrical grid, for example, includes both huge changes to move power from remote generation sites to the urban areas where it is needed, and the addition of storage or other mitigating measures to accommodate the intermittent nature of wind and solar. With regard to vehicles and fuels, there are changes needed such as modifying infrastructure to be compatible with ethanol or building huge numbers of charging stations for battery electric vehicles.

A method for handling these changes is to have a focus on designing the changes to the architecture, rather than letting them just evolve, and having the designs be flexible. This may be easier said than done, not only because it will be difficult to impose a design discipline, but because the existing architecture may be overly complex and as a result it may be difficult to design in the most efficient way. When working with legacy systems, which is the case for both electricity and vehicles/fuels, designing for ease of integration among independently-developed technologies is an important consideration. (Moses, 2004)

Another contextual consideration is the large amount of uncertainty surrounding just about everything when looking forward several decades. Uncertainty needs to be viewed not just in terms of risks, but also in terms of opportunities; these opportunities, as well as risks, need to be actively managed. Also, complex systems typically display emergent properties that were unexpected, further expanding the climate of uncertainty. Here again, embedding flexibility into system design allows the ability to capitalize on unexpected opportunities as they arise. (deNeufville, 2004)

\section{View Renewable Energy as Part of a System of Systems}

A primary cause of the resistance to change described above is that the energy systems in question are embedded in a system of interconnected contextual systems - economic and psychological/social, and the political behavior that emerges from the interaction of these with the US political system. While there is considerable investment in the existing infrastructure, the status quo is dictated as much by economic, political and social concerns as it is by this. Unfortunately, measuring, predicting and engineering these other systems may be beyond our ken. 
As an example, consider a utility that operates a fleet of pulverized coal (PC) power plants. This company is highly unlikely to write off such an investment and then turn around and invest in a multi-billion dollar fleet of concentrated solar power (CSP) plants to replace them. This is more than a considerable logistical problem; the upper management of the utility has varying levels of fiduciary responsibility to its stockholders, employees and customers, and must make decisions on that basis. This can be seen as an interaction of a physical system with a social one.

There are additional economic issues having to do with the supply chain, and while the utility's management does not have the same responsibility to the mining concerns and railroads that transport the coal, these too are affected. Spending billions to retro-fit the fleet with carbon capture and sequestration (CCS) technology is only marginally more palatable.

Social systems can provide resistance to change as well. In parts of the US where coalmining has been the economic backbone of the region for generations, there is more than an economic resistance to change. It can take on the aspect of family tradition. There can also be resistance to change due to nothing more than human nature. It is not uncommon to find skepticism towards the need to change something as pervasive as our energy system when the skeptic does not directly feel the effects of not changing, or when the effects of not changing are subtle; a small global average temperature increase from one year to the next is easily overlooked when the mercury dips below freezing and the snow starts falling in December. Such behavior may be difficult to model.

The foregoing shows that technology R\&D is not sufficient to advance the transformation of the US energy system. It may be, however, that research into the interaction of social and physical systems such as these can shed light on road-mapping efforts for more traditional technology R\&D. Such a meta-analytical/modeling approach allows us to view renewable energy $R \& D$ as a system of systems in its own right, comprised of DOE program $R \& D$, industry $\mathrm{R} \& \mathrm{D}$, foreign $\mathrm{R} \& \mathrm{D}$, cross-cutting $\mathrm{R} \& \mathrm{D}$ efforts from related areas (e.g. fossil energy), serendipitous scientific breakthrough, etc. This SoS is itself embedded in contextual systems described above.

\section{Apply Roadmapping Techniques to Renewable Energy Systems}

A roadmapping process is the appropriate first step in defining the energy world 20 to 40 years in the future. Roadmapping provides a structured way to approach the strategic planning process, while identifying barriers and uncertainties along various potential pathways. Ultimately, for an organization supporting the program management of DOE programs, the goal of a roadmapping process is to define an integrated path forward for government-sponsored Research, Development, Demonstration, \& Deployment (RDD\&D) activities.

A starting point for defining long-term energy pathways is to look at the desired end state. President Obama has defined two high-level, long-term goals: $25 \%$ of US electricity generated by renewable sources by 2025 , and $80 \%$ reduction in greenhouse gas emissions by 2050. In addition, twenty nine states and the District of Columbia have implemented renewable portfolio standards, with goals ranging from $2 \%$ up to $40 \%$ of electricity coming from renewables, with timeframes ranging from several years ago out to 2025; see Figure 2. 


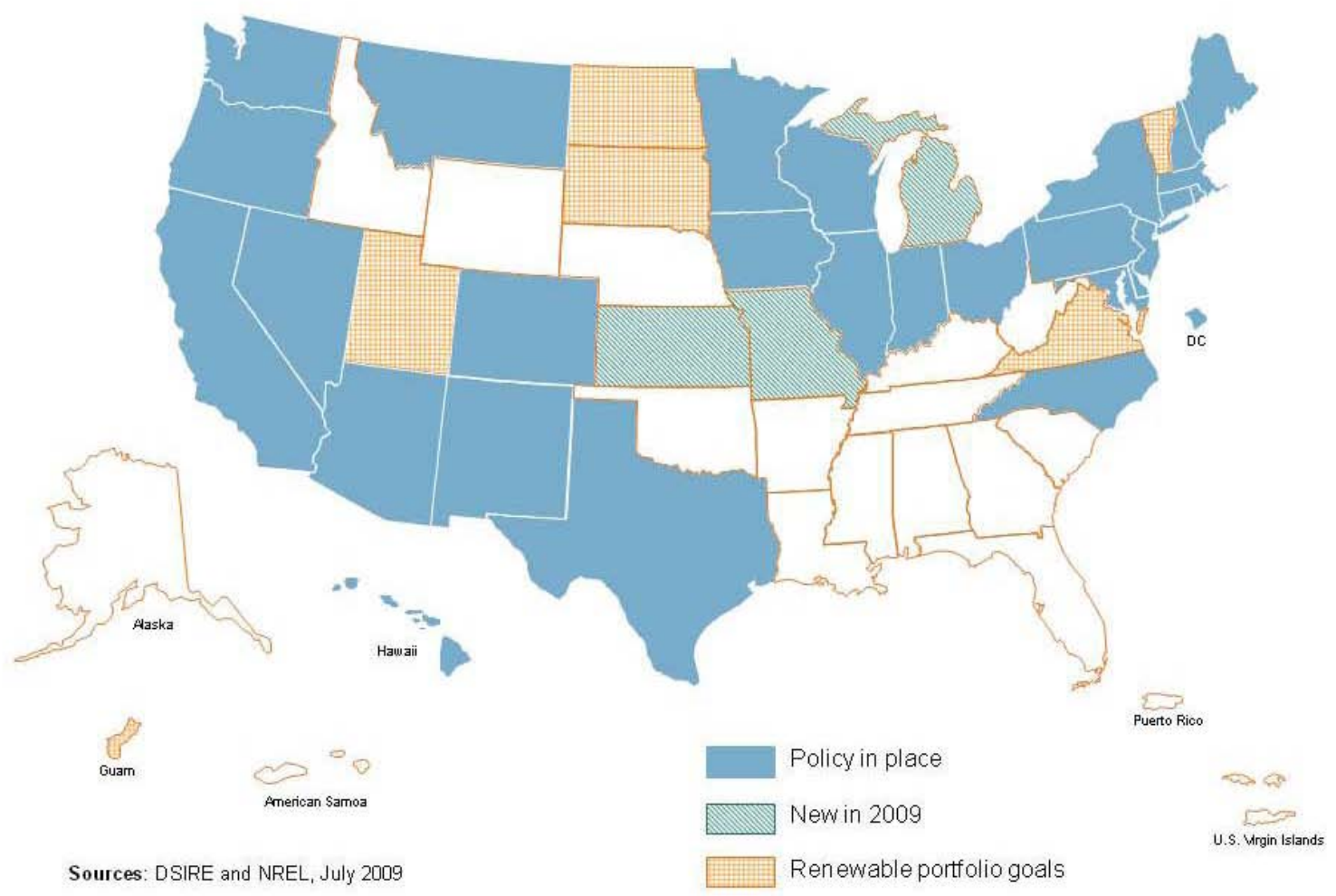

Figure 2. States with Renewable Portfolio Standards and Goals (Doris et al, 2009)

The long-term drivers for vehicles and fuels are also tied to greenhouse gas emission reduction goal, but other drivers include the improvement of economic and national security by reducing dependence on foreign energy imports. President Obama has defined two highlevel, long-term goals in this area as well: within 10 years save more oil than we currently import from the Middle East and Venezuela combined, and put one million plug-in hybrid cars on the road by 2015.

Armed with these high-level goals, the next step in the process is to try to envision a number of possible pathways leading to these goals. In order to develop this information, it is necessary to get the right participants involved in the process; for such a large and complex activity, this could be a challenge. However, Federal advisory committees are regularly formed to address special needs such as this, and many working groups already exist at various levels; the National Academy of Sciences is also tasked with addressing many bigpicture issues. In addition, the private sector does in some cases find ways to collaborate on technology development issues while maintaining competitive secrets; a good example of this is the International Technology Roadmap for Semiconductors, which develops fifteen year assessments of the semiconductor industry's future technology requirements.

The DOE will need to be the ultimate sponsor of this roadmapping activity, and it would be the entity that would publish the results. A great deal more specific planning will be needed to define the conduct of this roadmapping activity, but systems engineering principles will need to be at the heart of the process.

\section{Conclusions}

The adaptation of classical SE approaches to utilization in a renewable energy R\&D environment has been a challenging task. Enhanced use of modeling and simulation, along with application of emerging approaches to dealing with complex systems, are providing solutions to the unique needs of this environment. Continuing development of new 
approaches and tools for complex systems in the technical, socio-political, and economic arenas will be required to address the growing challenges surrounding large-scale deployment of renewable energy technologies.

\section{References}

DeNeufville, Richard, "Uncertainty Management for Engineering Systems Planning and Design", MIT (March 2004)

Doris, Elizabeth et al, "State of the States 2009: Renewable Energy Development and the Role of Policy", NREL (October 2009)

Duffy, Michael, "Systems Integration and the Department of Energy's Hydrogen Program", Proceedings of IEEE Symposium. (2007)

Duffy, Michael, Sandor, Debra, "A System-of-Systems Framework for the Future Hydrogen Economy", Proceedings of INCOSE International Symposium 2008. (June 2008)

International Council on Systems Engineering, "INCOSE Systems Engineering Handbook", Version 3.1. (August 2007)

Lawrence Livermore National Laboratory, Department of Energy, "Estimated U.S. Energy Use in 2008", LLNL (June 2009)

Moses, Joel, "Foundational Issues in Engineering Systems: A Framing Paper", MIT (March 2004)

Riley, Cynthia, Sandor, Debra, "Transforming From Petroleum to Biofuels: A System-ofSystems Perspective", Proceedings of INCOSE International Symposium 2008. (June 2008)

Ruth, Mark, "Macro-System Model”, DOE Hydrogen Program Annual Progress Report, U.S. Department of Energy (2009)

Sandor, Debra et al, "Understanding the Growth of the Cellulosic Ethanol Industry", National Renewable Energy Laboratory (April 2008)

\section{Biography}

Neil Snyder has been a practicing systems engineer and project manager for over 25 years. He has worked in the aerospace, defense, environmental, and energy industries, and has worked for a variety of companies including Lockheed Martin, Bechtel, CSC, SAIC, and Midwest Research Institute / Battelle; he is also a retired Air Force Reserve officer. He holds an MS degree in Civil Engineering and an MBA in Project Management, and is a registered Professional Engineer and a certified Project Management Professional. He is currently the Executive Director of Systems Engineering and Program Integration at the National Renewable Energy Laboratory in Golden CO, where he is leading efforts to address the very large scale issues relating to renewable energy development and integration.

Mark Antkowiak has been a practicing engineer for over ten years, and has been employed in a wide variety of technical capacities for nearly twenty years. He has worked predominantly in the energy sector, especially in renewables and nuclear. He has worked for a variety companies including WSRC, Energetics, Inc, CTC, EG\&G, and WorleyParsons. He holds a BS in Natural Science (physics, geology) and Psychology and an MS in Nuclear Engineering. He is currently a senior systems engineer with the Systems Engineering and Program Integration Office at the National Renewable Energy Laboratory in Golden CO, where he is primarily tasked to the Geothermal Technologies Program. 


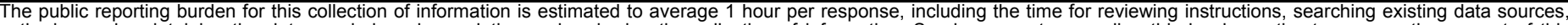

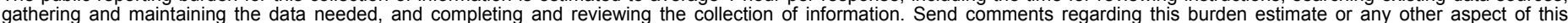

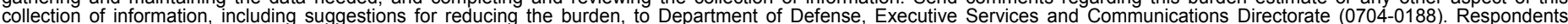

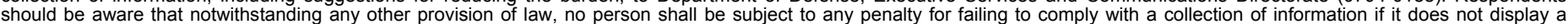

should be aware that notwithstanding

PLEASE DO NOT RETURN YOUR FORM TO THE ABOVE ORGANIZATION.

\begin{tabular}{l|l|l|l} 
1. REPORT DATE (DD-MM-YYYY) & 2. REPORT TYPE & 3. DATES COVERED (FrOm - TO)
\end{tabular}

April 2010

Conference Paper

4. TITLE AND SUBTITLE

Applying Systems Engineering in a Renewable Energy Research \&

Development Environment: Preprint

5a. CONTRACT NUMBER

DE-AC36-08-GO28308

5b. GRANT NUMBER

5c. PROGRAM ELEMENT NUMBER

6. AUTHOR(S)

N. Snyder and M. Antkowiak

5d. PROJECT NUMBER

NREL/CP-6A1-48159

5e. TASK NUMBER

6A10.0000

5f. WORK UNIT NUMBER
7. PERFORMING ORGANIZATION NAME(S) AND ADDRESS(ES)

National Renewable Energy Laboratory

1617 Cole Blvd.

Golden, CO 80401-3393

9. SPONSORING/MONITORING AGENCY NAME(S) AND ADDRESS(ES)

\section{PERFORMING ORGANIZATION REPORT NUMBER}

NREL/CP-6A1-48159
10. SPONSOR/MONITOR'S ACRONYM(S) NREL

11. SPONSORING/MONITORING AGENCY REPORT NUMBER

12. DISTRIBUTION AVAILABILITY STATEMENT

National Technical Information Service

U.S. Department of Commerce

5285 Port Royal Road

Springfield, VA 22161

13. SUPPLEMENTARY NOTES

14. ABSTRACT (Maximum 200 Words)

This paper examines lessons learned in systems engineering research and development at the National Renewable

Energy Laboratory and explores new ideas for future process enhancements.

\section{SUBJECT TERMS}

systems engineering; SE; renewable energy research and development; aerospace; defense; information technology; modeling; simulation

\begin{tabular}{|c|c|c|c|c|}
\hline \multicolumn{3}{|c|}{ 16. SECURITY CLASSIFICATION OF: } & \multirow{2}{*}{$\begin{array}{l}\text { 17. LIMITATION } \\
\text { OF ABSTRACT } \\
\text { UL }\end{array}$} & \multirow{2}{*}{$\begin{array}{l}\text { 18. NUMBER } \\
\text { OF PAGES }\end{array}$} \\
\hline $\begin{array}{l}\text { a. REPORT } \\
\text { Unclassified }\end{array}$ & $\begin{array}{l}\text { b. ABSTRACT } \\
\text { Unclassified }\end{array}$ & $\begin{array}{l}\text { c. THIS PAGE } \\
\text { Unclassified }\end{array}$ & & \\
\hline
\end{tabular}

19a. NAME OF RESPONSIBLE PERSON

19b. TELEPHONE NUMBER (Include area code) 